\title{
REFLEXÕES SOBRE A ESCOLA MBYA GUARANI: O MERO ESTAR AMBIENTAL E O CONHECIMENTO DA TÉCNICA
}

\author{
ROSEMARY MODERNEL MADEIRA ${ }^{l}$
}

UFRGS

\begin{abstract}
RESUMO: O presente artigo trata da relação dos Mbyá Guarani com a Escola e de sua aproximação do viver cidadão, incluindo a perspectiva do emprego, do ganho monetário e do consumo do objeto. Substanciado em Rodolfo Kusch e Martin Heidegger, o artigo busca uma visão do humano nas suas facetas antagônicas: o que crê no destino e se entrega ao mero estar ambiental e o que busca o ser alguém no afã da ética cidadã promulgada pela Escola. Através da análise dos textos e dos discursos de professores e lideranças, o artigo desenvolve-se tentando entender como os Mbyá apropriam-se da técnica cidadã, representada na Escola, para (re)inventarem sua própria técnica e (re)tomarem sua própria cultura.
\end{abstract}

PALAVRAS-CHAVE: educação; escola Mbyá Guarani; cultura Mbyá Guarani; ambiente.

ABSTRACT: This article is about the relationship between the Mbya Guarani and the School and about how they are getting closer to citizen life, including perspectives of job, monetary gain and consumption of the object. Substantiated on Rodolfo Kusch and Martin Heidegger, the article looks for a vision of the human in his antagonistic facets: the one who believes in destiny and surrenders to the ambiental "mere being", and the one who pursuits "being someone" on the effort of the citizen ethics, proclaimed by the School. Through the analysis of the texts and speeches from teachers and leaders, the article develops trying to understand how the Mbya take the citizen tecnique, represented in the School, to (re)invent their own tecnique and (re)take their own culture.

KEYWORKS: education; Mbyá Guarani scholl; Mbyá Guarani culture; ambient.

A Guapo'y Porã que conheci, pelos idos de 2004, está com os dias contados. A duplicação da rodovia levará o leito da estrada passar por sobre essa terra, mas a lembrança da roça cercada por taquaras e cuidada pelo Seu Horácio, karaí e cacique, do seu cão, o Petiço, dos animais domésticos, das pequenas bananeiras, do tanque de lavar

\footnotetext{
${ }^{1}$ Mestre em Educação pela UFRGS, Professora de Ciências no Centro Municipal de Educação de Trabalhadores Paulo Freire e de Ciências da Vida no Instituto de Educação Superior Sévigné, rosemadeira@hotmail.com .

${ }^{2}$ A aldeia Guapo'y Porã, Figueira Bonita, localiza-se às margens da BR-101, no município de Torres (RS). Com a duplicação da rodovia, seus moradores ainda se encontram em processo de discussão para novo assentamento até a presente data.
}

Espaço Ameríndio, Porto Alegre, v. 2, n. 1, p. 85-110, jan./jun. 2008. 
ROSEMARY MODERNEL MADEIRA - Reflexões sobre a escola Mbyá Guarani ...

roupas, do taquaral, da figueira que the empresta o nome, das mulheres lavando roupa e das crianças brincando no terreiro ainda me soam como atuais.

As visitas ocasionais à comunidade, excluindo as que assisti às aulas, as conversas sempre regadas a chimarrão, ocorriam na Escola ou na sombra das casas. Respondendo à minha indagação sobre o papel da Escola na comunidade, seu Horácio faz a ela sua crítica, mas entende que a aliança é necessária para que possa manter sua própria ética que nem sempre é igual à ética cidadã que a perpassa:

Eu vou dizer a verdade: a escola, por exemplo, tem parte é bom, tem parte não é bom, escola, para lo índio, é... porque lo índio vai começar a estudar, estudar, começar... lê bem, pero es que só lê bem porque não é como assim para juruá. Hum... Juruá, por exemplo, senhora, por exemplo... ficando estudando cinco, seis años, até oito, nove anos, pero es que no es, tem interesse ficar de motorista, ou doutora, ou médica mesmo, é... hum... ou trabalha restaurante, ou fica patroa, ou peão, ou qualquer coisa pensa grande, porque sabe bem que sem dinheiro ninguém não vai conseguir para comer. E índio não é assim, há um que lê bem, lo melhor, toma cachacinha e fica dormindo por aí. Não faz nada. Né? E é por isso que tem parte que eu entendo essa coisa que non serve para ler pra índio porque só lê, ou seja, lê bem, pero é que cada palavra ou cada letra ele ou ela no sabe o que significa (HORÁCIO LOPES, cacique da aldeia Guapo'y Porã, 19 jul. 2004).

A dúvida de Seu Horácio tem um significado profundo: lendo, o índio pode buscar o trabalho junto à comunidade "branca3"; tendo trabalho, recebe salário e, na presença do dinheiro, separa-se de seus preceitos básicos no afã de consumir os objetos ${ }^{4}$ que o "branco"

\footnotetext{
${ }^{3}$ Utilizo o termo branco/branca na própria acepção indígena daquele que não está na sua cultura e não no sentido normalmente utilizado de referência racial.

${ }^{4}$ A perspectiva heideggeriana de coisa-objeto é o do ser-simplesmente-dado, ou seja, os manuais, os instrumentos que, na sua instrumentalidade, saltam aos olhos num quarto como entes-intramundo e não como paredes que cercam este intra-mundo. O instrumento, desta forma, só é no uso, e sua totalidade referencial é revelada na descoberta do uso. As coisas já existem, porém a instrumentalidade é dada desde a alteração da forma na produção; "a própria produção já [é] sempre o emprego de algo em algo", embora existam coisas que se produzem a si mesmas, como os animais e as plantas; um martelo, um relógio, um alicate sempre farão referência àquilo que os produziu, o ferro, o aço, a madeira ou o couro. Porém, a obra produzida não se refere somente às possibilidades de emprego, como manual, mas também possuem o modo de ser do homem que a produziu e emprega. No mundo público, é numa obra que se descobre "a natureza do mundo circundante que, então, se torna acessível a qualquer um. Nos caminhos, ruas, pontes
}

Espaço Ameríndio, Porto Alegre, v. 2, n. 1, p. 85-110, jan./jun. 2008. 
ROSEMARY MODERNEL MADEIRA - Reflexões sobre a escola Mbyá Guarani ...

oferece, mas, mesmo que não seja isso, ser motorista, peão ou doutor, não é "ser índio", ou mesmo "há um que lê, lo melhor, toma cachacinha e fica dormindo por aí”. Não estará aí uma advertência de que ler o aproxima do "branco", mas, não tendo a vida do "branco", amarga sua frustração na bebida?

Pensar a Escola para os Guarani é pensar a possibilidade da assimilação, da perda da identidade e da cultura pela perda da língua. Há que tomar muito cuidado com este andar. São culturas diferentes que se colocam nesta arena: uma, o afã cidadão de "ser-aí", e outra, o demonismo vegetal de "estar-aí". ${ }^{6}$ O próprio Ser do Humano pode ser a vítima deste embate na fluidez alcoólica ou na perda das raízes, embora não se possa negar que a própria afanosidade ${ }^{7}$ não tenha sido de algum modo fagocitada ${ }^{8}$ pelo demonismo vegetal.

É interessante estabelecer um parâmetro entre cultura e o seu significado numa sociedade urbana e cidadã e aquilo que representa a cultura desde a perspectiva que ora falo. Para melhor introduzir este assunto, não posso deixar de buscar Kusch (1976, p. 69), quando

e edifícios, a ocupação descobre a natureza em determinada direção. Uma plataforma coberta leva em conta as intempéries; as instalações de iluminação pública levam em conta a escuridão, ou seja, a mudança específica de presença ou ausência da luz do dia, a "posição do sol". (...) no uso do instrumento relógio, manuseado discreta e diretamente, a natureza do mundo circundante também está à mão" (HEIDEGGER, 2002, p. 113).

${ }^{5}$ Na perspectiva de Heidegger (2002), o ser-aí, dasein ou pre-sença não é sinônimo de humano, ser humano ou de humanidade, mas sim é processo de constituição ontológica do humano, ser humano e humanidade.

${ }^{6}$ Kusch (1986) afirma que empregar o conceito de estar como qualidade de uma cultura não deixa de ser uma heresia filosófica, embora afirme que dasein heideggeriano possa ter o sentido de mero estar - darse. Por outro lado, ao discutir a influência da paisagem no agir autóctone, utiliza o termo demonismo vegetal (KUSCH, 1953), apresentando-o como uma forma de perpetuação do humano frente à paisagem, pois tal como o vegetal supera a inclemência ambiental, o humano tende a copiar este constante retorno como uma forma de superar o medo maior, o medo da morte, com a idéia de destino.

${ }^{7}$ Kusch (1986) traz o conceito de afanosidade como uma característica do europeu cidadão que aqui chegou e se contrapõe ao mero estar autóctone. O sentido dado é o afã de ser alguém.

8 Kusch (1986) discutindo o termo "aculturação" no encontro da Europa cidadã e da América agrária, admite-a em relação a elementos, tais como a vestimenta e a arquitetura; porém, por outro lado, diz haver uma fagocitação do europeu pelo "ser americano" no que tange, especificamente, à ação do próprio ser na sobrevivência, sua impregnação pela paisagem, pela tragédia do viver na economia ditada pelo ambiente, onde o fruto (maiz) pode acontecer ou não $\mathrm{e}$, neste caso, há que poupar as parcas energias para a comunidade e, nisto tudo, a indiferenciação do meio, onde a "ira de Deus" pode ser acalmada pelo sacrifício. Diz o autor (1986, p. 173-174): "La fagocitación no es consciente sino que opera más bien en la inconsciencia social, al margen de lo que oficialmente se piensa de la cultura y de la civilización. (...) Pero la fagocitación se da ante todo al margen del crecimiento material, en esa trampa que es la intimidad de cada uno. Indudablemente la adquisición de objetos, seguirá hasta el infinito, pero es evidente que nunca podrá convertirse en el móvil central de la vida. El objeto no es más que cantidad o cualidad, pero nunca algo sustancial. Más aún, vivir es estar firmemente aquí y eso se da al margen del objeto: el terreno de la comunidad, el fruto y la presencia de la ira".

Espaço Ameríndio, Porto Alegre, v. 2, n. 1, p. 85-110, jan./jun. 2008. 
debate o que é cultura desde a ótica cidadã e sua perspectiva de beleza, "que [busca] armonía exterior a nivel decorativo (...), un objeto fácil de consumo, como que se colocaba en el comedor donde se reunía la familia". Nesse debate, o autor tenta mostrar a necessária palatividade daquilo que vulgarmente se entende por cultura e a permanência histórica e consumista em que se dá o valor à obra enquanto mercado de consumo. Porém, quando discute a cultura autóctone, aponta uma diferença primordial, sendo ela o próprio movimento dinâmico que se contrapõe aos valores dados à cultura na perspectiva cidadã:

\begin{abstract}
Algunos antropólogos pretenden que una cultura se conoce haciendo un recuento de los objetos culturales del indígena. Craso error. Es un criterio propio de la burguesía norteamericana. Ésta no sabe que la cultura indígena no es estática, sino dinámica. Su valor no se da en el inventario sino en la función. Puedo describir un sacrificio de sangre, pero el sentido real de éste aparece recién cuando yo mismo lo efectúo para resolver un problema vital de mi comunidad. La cultura indígena es una cultura ritualizada. Por eso los indígenas nunca recuerdan bien en qué consiste ella. No tienen el inventario de su cultura. ¿Por qué? Porque su cultura está en función de su sentimiento de totalidad y éste no se expresa sino en su ritual. Sólo así el indígena consigue afirmar sus raíces existenciales (KUSCH, 1976, p. 69).
\end{abstract}

Quando Kusch afirma que "la cultura indígena no es estática, sino dinâmica", aproxima-se de Pinker (2004, p. 101) quando afirma que culturas tomam empréstimo de outras, as práticas que funcionam melhor, e que, "longe de serem monopólios autopreservativos, as culturas são porosas e fluídas". Buscando entender este dinamismo na cultura Mbyá, procuro traçá-lo em um texto produzido pelo professor Hugo e traduzido por Verá Pothy 9 :

Nhande mbya kuery ma tẽgua heteaeri jareko teko ymaguare, ha eva'epy jepema ore pexa ipyau kuevegui ndoroikuaa veima, mamoguipa romonhepyrũaguã teko ymaguare kyrĩguepe, ha upeiave anhetẽari teko yma'guare nhamombe'uva'erã,

\footnotetext{
${ }^{9}$ Todos os demais textos, à exceção dos trabalhados em aula pelo professor Hugo, foram traduzidos por Vera Pothy.
}

Espaço Ameríndio, Porto Alegre, v. 2, n. 1, p. 85-110, jan./jun. 2008. 
ROSEMARY MODERNEL MADEIRA - Reflexões sobre a escola Mbyá Guarani ...

kyrĩguepe oikuaaguã ima endu aaguã ha upei, onhogatuaguã oakãmy ndopaiaguã:

Ima endú aa teko ymaguaregui ikatuaguãĩxa agỹgui jepe kyrĩgue oiporuju, Nhande reko ymaguare he'ỹramoma hoikuaaguãjepe ha evyma ore pexa ronhepyrũta ronhemboatypy, ronhepyrũta mokoĩayu pymavoi rombo etaeravy, rombo eta mboraire nhandepy romombe uta teko ymaguare, vixo-irekorue nhande ramoi rekokue, Mba eiko teko ymaguare ha eveva eterei nhandevy, ha'e pavẽpe. Nhamombaraeteaguã nhande mba apoá, nhembo eapygua, mba eiko nhande nhanhombo eva ekuery, nhanha ãavi va erã jaeko jouaguã ha evea irupi.

Jaraa porãve aguã nhandereko.

Ha evina ore tekoa guapoy pygua. Rojapota peteĩ teko ymaguare nhemombe'u kuaxiare.

Rombo parata rombombe u mba exapa vixo i oke Nhande ramoĩpa mba exa ojuka raka'e xi'ype koxipe guaxúpe mba'e ara ruparepa guyra ombo'a ha upe ta'y ha eva e ha-ejavi romoita kuaxiare ${ }^{10}$ (HUGO FRANÇA apud DORNELES et al, 2005, p. 36).

A dinamicidade da cultura, associada à própria aproximação, deixou para trás, muito longe, a história do povo, a aproximação com o natural, o próprio ciclo da vida e seus tempos. Talvez pela regulação da eletricidade não mais conheçam as horas ditadas pelo movimento sideral do planeta, o tempo da postura e o tempo de nascer. Mas, o inventário de sua própria cultura aparentemente é desnecessário porque a Opy ainda abriga os instrumentos musicais que louvam Ñanderu, e ainda o karaí é capaz da cura com suas rezas e suas plantas. Talvez o

\footnotetext{
10 No fundo, existe um próprio jeito de ser Guarani, mas nós que somos mais novos, já não lembramos mais tudo isso, por isso não sabemos direito de como e de onde começar para dar os nossos costumes milenares para as crianças, mas temos que se esforçar para dar este costume para as crianças para eles saberem, lembrarem, e guardarem para nunca terminar, porque se eles lembrarem, com certeza todos nós teremos nossas vidas milenares, como antigamente, ou se não, só para eles saberem nosso próprio jeito de ser.

E agora nós vamos começar aqui na nossa escola, vamos começar ensinando nas duas línguas, vamos ensinar os cantos na nossa língua, vamos contar um pouco das vidas milenar Guarani, um pouco da vida dos bichos, e como era a vida dos nossos velhos, e tentar entender, porque vidas milenares eram muito valiosa "tekó porã" para todos nós, ter esta vida e ter força no nosso trabalho de ser professor, porque nós que somos professores temos que agüentar tudo que vem de mal em nossos caminhos para conseguirmos ter esta força que vem da vida milenar Guarani, e assim teremos a capacidade de ensinar as crianças irem pelo caminho certo e nossas vidas também.

E agora, nós da aldeia Guapo'ý, vamos fazer um estudo das vidas milenares nos nossos cadernos.

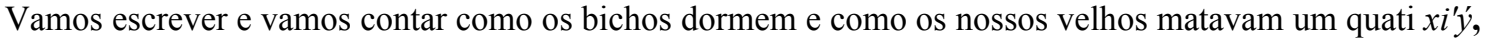
um porco do mato koxí, um veado guaxú, em que mês os pássaros chocam seus ovos, e em quantos dias nascem os filhotinhos. Tudo isso escreveremos nos nossos cadernos.
}

Espaço Ameríndio, Porto Alegre, v. 2, n. 1, p. 85-110, jan./jun. 2008. 
ROSEMARY MODERNEL MADEIRA - Reflexões sobre a escola Mbyá Guarani ...

papel da Escola, neste contexto, seja o de inventariar o modo de ser Guarani para lembrá-lo, já que os Guarani são e permanecem.

A Escola, na ótica daqueles que defendem sua permanência na aldeia, deve configurar-se como um ponto estratégico de resistência e manutenção da cultura. Embora se possa observar que seus parâmetros são muito assemelhados aos que trabalhamos nós, professores "brancos" (classes, quadro de giz, cadernos e canetas), há um pensar no como se pode fazer diferente. Várias idéias surgem para definir o currículo.

Ler e escrever é fundamental, ler e escrever em guarani e em português. Porém, para além disso, ensinar as tradições, o como caçar, o como se vê o mundo, que roupas são tradicionais, que alimentos são saudáveis, quais animais eram comuns por essas paragens e que animais ainda se podem conhecer...

Em relação a isso, há o depoimento de Marcos Tupã (Cacique da Aldeia Krukutu, SP, entrevista em 19 fev. 2005) que, quando um Guarani das outras reservas comunica ter visto um animal de grande porte e em extinção, ele, imediatamente, leva as crianças para observá-lo, para que elas possam só conhecê-lo, “...já tem pouquinho, ainda vai matar o pouquinho que tem?". Na aproximação com o texto do professor Hugo, começa a fazer sentido a diferença cultural imposta pela aproximação e pela degradação propiciada pelos muros da cidade: "Vamos escrever e vamos contar como os bichos dormem e como os nossos velhos matavam um quati $x i^{\prime} y$, um porco do mato koxí, um veado guaxu, em que mês os pássaros chocam seus ovos e em quantos dias nascem os filhotinhos. Tudo isso escreveremos nos nossos cadernos".

O fazer do material didático das aldeias falam de matas, de mundéos, de moradias tradicionais, de vestimentas, de Pindó, a palmeira mítica que origina o mundo e dá a fibra para a fabricação das roupas, dos arcos e das flechas.

No dia de Matemática, chamou-me atenção a forma de representação dos números que fugia à regra gráfica dos ditames escolares cidadãos e, para além da alteração nos sinais gráficos, Hugo usa outras formas de representar, tanto pictoricamente quanto oral e escrito. A forma de contar quantidades tem representação própria até quatro e, a partir daí, resulta de adições e divisões estratégicas, por 
ROSEMARY MODERNEL MADEIRA - Reflexões sobre a escola Mbyá Guarani ...

exemplo, o cinco pode ser chamado de irundy peteĩ vê, ou seja, quatro mais um; o seis, por mboapyapy, ou seja, dois três; o sete por irundymboapy, quatro mais três. Já o prefixo ja'o representa a metade de algo; portanto, pode ser o cinco metade de dez. Mesmo para as operações propostas, são usados outros símbolos, tais como uma flecha com duas pontas, kue, que representa a multiplicação, uma flecha apontada diagonalmente para cima, ojeupi, a adição, uma flecha apontada diagonalmente para baixo, ogueji, a subtração, e, finalmente, três flechas partindo de um mesmo ponto, boja'o, a divisão.

O professor Hugo parece inconformado com o uso dos símbolos gráficos dos juruá. Digo isso porque, embora use o alfabeto para escrever as palavras em Guarani, ele faz questão de frisar que o alfabeto próprio é diferente daquele que nós usamos, pois apresenta menos letras e algumas que não utilizamos ${ }^{11}$. Feita esta diferenciação, restouIhe modificar também a representação numérica: cria símbolos que representem as quantidades e que tenham alguma representatividade no Ser Guarani. Alterando a simbologia, pode até confirmar que os números por eles usados são copiados pelos juruá - como está explícito no símbolo representativo do sete ${ }^{12}$ ou, então, são representações da tradição deste povo, como as flechas, as lanças, os arcos... objetos que já não fazem mais parte do cotidiano da vida indígena e que, na realidade atual, são artesanatos que se produzem para venda aos "brancos", plenamente enfeitados com penas de galinhas tingidas com corantes industriais.

Não deixa de ser comovente a forma como a tradição perpassa cada um dos caracteres cuidadosamente inventados pelo professor ${ }^{13}$ : trazer a imagem da flecha e do arco e da valentia do índio que não precisa mais que uma flecha para conseguir seu sustento e livrar-se do inimigo, trazer os animais na figura do sapo que pula para representar quatro unidades ou das plantas sagradas, como um folíolo, que representa oito unidades, da folha composta por oito deles da farmacopéia Guarani.

\footnotetext{
${ }^{11}$ São elas: A, B, D, E G, H, I, J, K, M, N, O, P, R, T, U, V, X, Y, recortadas e coladas em um cartaz afixado na sala, ao lado do quadro de giz, onde se desenvolvem as aulas.

${ }^{12} \mathrm{Na}$ explicação do Hugo, originariamente os "brancos" usavam o arco e a flecha para representar sete coisas, mas para ficar diferente dos índios retiraram a corda, ficando somente a madeira do arco e a flecha, ou seja, a representação 7.

${ }^{13}$ Observar tabela em anexo.
} 
Uma das aulas de Matemática era sobre as operações que se fazem quando de trocas monetárias. Para isso, Hugo trazia problemas ${ }^{14}$ de compra e venda, mas antes fez algumas operações simples, tais como a leitura oral das representações pictóricas numéricas, cálculos mentais de proposições escritas, para, finalmente, então, propor problemas em que fazia a leitura oral (no que era secundado pelas crianças), sempre com a correção da pronúncia:

\begin{abstract}
Mba'emo repykue mboery mbovypa oipity ho'upei hemby mab'emo repykuery. Ha'i ojongua irundy merõ. Ha'i ojogua irundy merõ. Ha'ema oguereko mba'emo repy. Gui mbovy tu hemby ojo guaramo irundy merõ petei teire ${ }^{15}$ (anotações da aula do professor Hugo França, 26/07/2004).
\end{abstract}

Falar de dinheiro numa sociedade de trocas, trocar papel por alimento e, antes disso, trocar os utensílios com os quais traziam os alimentos para casa por papel, relações plenamente normais e plausíveis numa escola de uma cidade qualquer, revestem-se de estranheza para quem não coloca sequer uma cerca no entorno de sua casa, pois a sociedade Guarani baseia-se na reciprocidade e

la reciprocidad es la matriz por la cual los hombres se reconocen como seres humanos y también el espacio social dentro del cual las acciones y las cosas encuentran su valor y su sentido, incluyendo las prestaciones económicas (MELIÁ e TEMPLE, 2004, p. 69).

Ou seja, "cuanto más doy más soy" (MELIÁ e TEMPLE, 2004, p. 69). Isto acarreta uma degeneração de crescimento de importância na doação, pois quem busca doar é mais do que aquele que só recebe, de tal forma que se torna um processo hierárquico em que, quem não pode dar, torna-se um desqualificado social.

As andanças entre as aldeias, ou seja, o receber e visitar parentes, mostram esse processo. É sinal de prestígio ser visitado, e essa visita

\footnotetext{
${ }^{14}$ A tradução do texto é feita pelo próprio professor no decorrer da aula e repetida pelos alunos em voz alta. Tenho-as anotadas em meu Diário de Campo e gravadas em fita K-7.

${ }^{15}$ Nós falamos de dinheiro. Quanto vai custar depois, quanto vai sobrar de dinheiro. Ela comprou quatro melões. Ela tem dinheiro, dez reais. Quanto sobrou se ela compra de quatro melões?
}

Espaço Ameríndio, Porto Alegre, v. 2, n. 1, p. 85-110, jan./jun. 2008. 
ROSEMARY MODERNEL MADEIRA - Reflexões sobre a escola Mbyá Guarani ...

sempre espera por uma retribuição. Quem recebe, arca então com a alimentação e a moradia do hóspede. Nos tempos de fartura, de boa terra, de plantações bem sucedidas, esse receber é uma festa, mas, quando não há mais mata onde buscar alimento ou terra para o roçado, ele torna-se problema.

Numa de nossas conversas sobre roupas, ouvi um dos que conversava afirmar que o uso da vestimenta foi ensinado pelos Mbyá aos juruá, quando ambos se encontraram. Não sei se a fala, nesse momento, referia-se ao fato da diferença climática encontrada pelos aqui chegados ou, simplesmente, uma revisitação histórica, tal qual entendo como revisitação as ruínas que o Kechuíta deixou na sua passagem pela Terra. Porém, tenho um texto do professor Hugo que lembra a forma e o material primordial da feitura daquilo com que se cobriam os Antigos:

Teko yma, mãje agỹguagui, amboaenda ramiete raka'e mba eiko yma nhaneretarã kuery mba'eve ndoikuai ho'u va'erã gui oiporu va'erãgui, ha'eramivy ha'ekuery ndo'ui raka'e juky, nhandy, ndoiporui mbo'ká, kavõ, juú ni aó nomoĩ.

Avakue hambeó raka'e tambeó rãma ojapo pyno piregui omboyvi oipopẽ, kunhague-ma omoĩ raka'e tupyjaá, tupyjaa-ma ojapo raka'e nhepỹrũete'i maja ojapó pindogui. Ojaya pindo hi'ygue oipe'ã ombo'iporã ho'okue omboyvi omoĩrũ pindo roguepy. Hoguepy ombopya avaxi pirepy ombo ku'a, omemby'i omondeaguã reve voi avaxi pire oipoka ${ }^{16}$ (HUGO FRANÇA apud DORNELES et al, 2005, p. 28).

Hoje os Guarani têm uma forma toda especial de se vestirem: os jovens usam calças largas, de cintura caída, cobertas por longas camisetas, mas adornados com todos os colares que são capazes de produzir. As mulheres conservam suas longas saias, às vezes adornadas de babados, e os homens vestem-se à maneira da população cidadã de

\footnotetext{
${ }^{16}$ A vida antiga dos guarani era muito diferente da vida de hoje, porque naquela época os nossos parentes não conheciam comidas nem objetos da sociedade branca. Por não conhecer, eles não comiam sal, banha, não usavam espingarda, sabão, agulha e nem usavam roupas.

Os homens usavam tanga "tambeó"; para fazer a tanga usavam casca de urtiga gigante "pynó". Tirava a casca do pynó e trançava. As mulheres usavam saias feitas de caule de palmeira "tupyjaá". Para fazer saia cortava um bom pedaço de caule de palmeira, partir bem e tirar as linhas e trançar com suas próprias folhas e a cintura era feito de palha de milho, as palhas serviam para duas coisas, para cintura e uma parte dela servia para carregar os filhos.
}

Espaço Ameríndio, Porto Alegre, v. 2, n. 1, p. 85-110, jan./jun. 2008. 
ROSEMARY MODERNEL MADEIRA - Reflexões sobre a escola Mbyá Guarani ...

baixa renda. Já não se servem mais do pynó e da palmeira pyndó na confecção de suas roupas, já que essas são buscadas nos mesmos lugares onde os juruá menos afortunados pela sorte buscam: nos empórios populares de nossas avenidas comerciais. Porém, essa história não pode perder-se, nem a importância das sagradas plantas que cobriam a pele e protegiam-na contra as intempéries do azar. Sobra à memória o uso da tambeó e da tupyjaá, agora feitos de algodão industrializado, para as apresentações do coral, em que o canto Guarani ganha os céus nas vozes de seus kyrĩgue (crianças).

Por outro lado, é o alimento um dos motivos que os leva ao movimento em direção à cidade. O artesanato (a cesta, por exemplo) que antes buscava o alimento nas roças, hoje é vendido nas cidades, trocado por papel que se transmuta no milho, na mandioca, no amendoim e que farão a alimentação da comunidade. De qualquer forma, são os cestos que ainda trazem a abundância, não mais carregados com os frutos da terra, mas trocados pelo princípio instituído pelos "brancos", a sociedade ocidental do mercado. O ajaká, que antes buscava a fartura na roça, traz a fartura na forma de papelmoeda; os pequenos animais entalhados e os vistosos colares de sementes já não servem somente ao adorno: eles também garantem o sustento comunitário.

A tradição do povo perpassa sistematicamente os fazeres da aula, como no exemplo da aula de Ciências, em que, além de ensinar o nome dos animais - que as crianças já não têm mais o contato físico, pois rareiam nas periferias urbanas -, é-lhes ensinado como se faz a roça e quais instrumentos são usados para sua execução. A escrita e a fala guaranis precedem a escrita e a fala em português em todos os momentos da aula e são usadas para descrever o modo de Ser Guarani. Observo que há muitas comparações com o "antigamente" e, tendo o passado como base, a Escola busca ensinar como se comportar, quais valores são importantes e de que identidade se fala quando o coletivo é familiar e aldeão. A fala é sempre uma busca das coisas que se esqueceram no caminho, como exemplifico nos escritos copiados do quadro e traduzidos pelo professor:

Mba exa nda'u mbya kuery ikusi ra ka'e yma ha upeiagỹ ave Mba eiko agỹ opamba'e i ma py 
ROSEMARY MODERNEL MADEIRA - Reflexões sobre a escola Mbyá Guarani ...

nhapondera nda jakuaa paive'ma yma guare teko mabae'e pa ho'u ojuka ${ }^{17}$ (anotações da aula do professor Hugo França, 22 jul. 2004).

O texto é copiado pelos alunos e, posteriormente, é feita a tradução oral que também é repetida oralmente por eles. A escrita em português é quase inexistente; há um português falado pelo professor que os alunos tentam acompanhar, no entanto sem estabelecer que ou o quê está representado graficamente no quadro.

Em cada dia de aula, Hugo trazia os conhecimentos de alguma maneira semelhantes à forma da Escola ocidental, ou seja, há o dia de Ciências, o dia de Música, o de Língua Portuguesa, o da Matemática... Nos dias de estudos de Ciências, os tópicos buscados eram os animais que podiam ser caçados ou como se faz uma horta ou como se pode viver com saúde desde a tradição Guarani ou, ainda, das origens da Terra e da vida:

Ye'ẽ tuixa yvyrami avi. Pero há'ekuery ma jaupive onhembo jera va'ekue. Ha'upei pe mava'epa ombojera raka'e yvy pe. Ha'upei ye'ẽ pe ha eva'e ma nhanderuae raka'e ombojera oiko aguã pira ha upei mymba ka'aguy ave oikoagua yvy ary ${ }^{18}$ (anotações da aula do professor Hugo França, 22 jul. 2004).

A análise do texto, centrado na ótica do fazer divino que propõe um mar e uma terra onde os animais vivem juntos, remete à transformação do mundo desde um ser humano, um karai xondaro, que se propõe a dar seu corpo para que este se transforme na Terra. Saber que tudo o que cerca é uma proposta divina, feita não mais para gozo do humano e sim um local "para viver os peixes e animais selvagens pela Terra", coloca não mais nas mãos do ser do humano a transformação, retirando a ótica de intervenção e afirmando a de aproximação com aqueles para quem "Deus fez o mar e a terra".

Dessa forma, na aula que ensina como fazer uma roça, o professor Hugo escreve no quadro o texto “Kokue regua: Meba exa nhi'ã onhoty kokuepy: Ojo’o omboakua yvyra. Há'eryma onhepyty võuka

\footnotetext{
${ }^{17}$ Como será que os antigamente guarani vive e agora também. Porque agora estranhamos todas as coisas. Já não conhecemos mais as histórias antigas. De que tipo ele comia e matava.

${ }^{18} \mathrm{O}$ mar é grande como a terra, mas se surgiram juntos. E daí quem é que surgiram: a terra e o mar. Isso foi o Deus que faz isso para viver os peixes e animais selvagens pela Terra .
}

Espaço Ameríndio, Porto Alegre, v. 2, n. 1, p. 85-110, jan./jun. 2008. 
ROSEMARY MODERNEL MADEIRA - Reflexões sobre a escola Mbyá Guarani ...

mokoĩpe omoĩaguã mba emo ra yĩ gue'i'19" (anotações da aula do professor Hugo França, 20 jul. 2004), usando uma leitura oral e tradução simultâneas.

O professor associa o texto à saúde do povo Guarani, ou seja, é desde plantar a roça e colher o alimento puro que a saúde se estabelece, e esta saúde está também no ajudar-se, nas pessoas que, juntas, podem produzir o que lhes alimentará; "depois eles pedem ajuda para duas pessoas para botar sementinha". Duas pessoas são necessárias para colocar a "sementinha" no solo; duas pessoas são necessárias para "unir sementinhas" que originarão um novo ser semelhante a elas, que precisarão de ajuda para colocar a "sementinha" que fecundará a terra e produzirá o alimento para a saúde do povo Guarani.

Em relação ao ensino de Ciências numa Escola Guarani, é importante observar que a explicação científica, comum na Escola cidadã, não é a que melhor orienta o pensamento do professor Guarani. Desse modo, as explicações dos Guarani podem associar o mito ${ }^{20}$, contar a tradição, explicitar as ervas necessárias à cura e descobrir que animais são importantes no Nanderekó.

O texto que reproduzo a seguir dá uma idéia de como a tradição mitológica está presente no dia-a-dia da sala de aula ${ }^{21}$ :

\section{Avaxiete'i oikóague}

\footnotetext{
${ }^{19}$ Sobre a roça - Como planta uma roça: cavoucar e fazer a pontinha do pau. E depois eles pedem ajuda para duas pessoas para botar sementinha.

${ }^{20}$ Tenho anotado em meu diário de campo uma história que ilustra esta afirmação. A história ocorreu com a professora "branca" da aldeia Jata 'ity: "questionada pelo professor indígena como ela ensinaria um raio numa tempestade, ou o que era um raio, a professora trouxe a explicação que era uma reação energética entre a nuvem carregada e terra. O professor argumentou que esta é a explicação do branco. $\mathrm{O}$ raio, disse ele, é mandado por Ñanderu para castigar a árvore que não foi gentil com as crianças que com ela queriam brincar. A professora reagiu à explicação, mas foi contra argumentada pela afirmação que o branco não sabe disso porque Ñanderu contou isto aos índios e não aos demais".

${ }^{21}$ O Projeto Formação de educadores na perspectiva da escola bilíngüe guarani-português e produção de coletânea de textos bilíngües para uso como material didático e de formação docente, foi desenvolvido em parceria - FACED - Faculdade de Educação, IFCH - Instituto de Filosofia e Ciências Humanas e o IE - Instituto de Letras da Universidade Federal do Rio Grande do Sul, com financiamento da Sesu-MEC, através do Programa de Apoio à Extensão Universitária voltada às Políticas Públicas. As discussões contavam com participação da comunidade nas pessoas de suas lideranças - karaí, cuña karaí, caciques, professores e os velhos das aldeias. Do projeto resultou um livro com textos escritos pelos professores Agostinho Verá Moreira - Escola Estadual Indígena Karaí Nhe’e Katu - Estiva, Marcos Verá Moreira Escola Estadual Indígena Karaí Arandu - Cantagalo, Jerônimo Franco - Escola Estadual Indígena Teko’á Porã - Coxilha da Cruz, Paulo Morinico - Escola em processo de implantação - Lomba do Pinheiro, Hugo França - Escola Estadual Indígena Guapo’y Porã - Figueira Bonita, publicado pela Secretaria Estadual de Educação do Rio Grande do Sul.
}

Espaço Ameríndio, Porto Alegre, v. 2, n. 1, p. 85-110, jan./jun. 2008. 
Mbya avaxi-ma jurua avaxigui amboae'iju.

Mamoguipa ojou raka'e avaxiete'i oikoaguã mbya kuerymba'e?

Nhepyrũ guima nhaneretarã ikuai raka'e ka'aguyre mba'eve ndoguerekoi raka'e onhotỹ va'erã kokuepy mbyaete'i, ha'evy-ma heta ikuai peteĩ' ĩ tekoapy, pero oiko mboapy xondaro ka aguyre ikyre' $\tilde{y}$ va'e ha'evyma ojogueraá jepi ka aguyre ha'e mba'eve teri ndojoui.

$\mathrm{Ha}$ ekuery onhotỹ va'era. Rire ma mboapy xondaro oó riae vy, oexama peteĩ xondaro oma'ẽ ma'ẽvy yvyrare aka'ẽ mokoĩ hiny yvyrare amboae ma ovaẽ ramove oveve ovy. Yvygui oma ẽ porã ramo-ma ixĩ iky'aparei oiny.

Ha'eramo-ma xondaro ojevyju goópy.

Hare rirema ooju ha'ekuepy ha evy ma avaxi henhoĩ ma okuapy mboapyregua, ha'eramo xondaro ogueraá mokoĩ'y oexaukaaguã pavẽpe.Ha eramo amboaekuery onhemondyipa okuapy oexavy. Ha'eguima onhepyrũ-ma onhotỹ okuapy pavế tekoaygua oguerekoaguã ojeupe guarã avaxiete'i, agỹrereve oiko ${ }^{22}$ (HUGO FRANÇA apud DORNELES et al., 2005, p. 29).

O milho serve como subsistência e princípio de organização das roças, das festas, do pão que sacia a fome. Nas diversas roças que conheci nas minhas andanças, por mais variedades que houvesse, sempre o milho ocupava o lugar de destaque, tanto nas conversas, como as dádivas que recebemos nas nossas visitas às Teko'á.

Os Guarani têm um manancial próprio de sementes que trocam entre si e que buscam nas matas para repovoar os lugares onde fazem suas moradias. O milho Guarani caracteriza-se pelas cores variadas e,

\footnotetext{
${ }^{22}$ Milhos Guarani.

Milhos Guarani são diferentes dos milhos dos brancos. De onde surgiu esse milho Guarani e como eles descobriram que o milho era para eles?

No começo, os nossos parentes viviam na mata sem ter nada para plantar nas suas roças. Eram bastantes Guarani que viviam em uma aldeia e nesta aldeia havia três rapazes (xondaro) que gostavam de caçar e todos os dias eles iam no mato, mas nada eles tinham conseguido de sementes que podiam plantar para sua sobrevivência.

Mas, como a caça dos três rapazes (xondaro) era todos os dias, chegou a hora de um rapaz dar uma olhada sozinho e ele olhou numa árvore e viu dois tucanos, mas quando ele se mexeu foi [o tucano] voando e quando ele olhou para aquele tucano que ficou, ele estava com o bico sujo de terra. Daí o rapaz (xondaro) voltou para sua casa. Outro dia ele foi de novo ao mesmo lugar onde viu os tucanos e lá estava os três pés diferentes de milho, e cada espiga era diferente do outro e o rapaz levou duas espigas para mostrar à sua comunidade e quando ele mostrou todos ficaram assustado com que ele tinha achado. Então, a partir deste dia, começaram a plantar o milho que o rapaz tinha achado. Essas três espigas de milho deu para todas as famílias da comunidade e assim foram aumentando a quantidade de milho e nunca mais perderam. Por isso até hoje existe milho Guarani.
}

Espaço Ameríndio, Porto Alegre, v. 2, n. 1, p. 85-110, jan./jun. 2008. 
entre eles, um de pequeno tamanho, o avaxi mitã/milho criança, coisa com a qual eles brincam dizendo que, sendo pequenos, os pés de milho devem também ser pequenos e não grandes como os dos juruá.

A forma de intervenção no ambiente acontece na queimada, no roçado, na plantação agrícola, mas também no repovoamento do espaço ocupado, buscando o princípio do Tekó, para que se possa ter uma Teko'á. Dessa forma, há que narrar a luta de seu Turíbio, velho morador de Itapuã, com os eucaliptos. Reproduzo um fragmento de seu discurso, proferido por ocasião do "Seminário Terras Guarani no Litoral Contexto Fundiário e Ambiental"23:

Uma semana depois de eu estar lá, no meio dos eucaliptos, no outro dia, chegou calcário. O que eu vou fazer com calcário? Adubar a terra para nascer mais eucalipto? Pra nascer mais eucaliptinho? Jogado no lixo eu tô. Nem água tenho. Tenho que comprar do meu vizinho. O governo não vende a água da Lagoa dos Patos. Por que eu tenho que comprar? Aquele português que disse que descobriu o Brasil, que o país era branco. Que nada! Já estavam os índios aqui (TURÍBIO NHENGATU GOMES, Cacique da Aldeia Pindó Mirĩ, anotações do discurso, 17 fev. 2005).

A "guerra" de Seu Turíbio com os eucaliptos é sem trégua. Cortou todos os que existiam no entorno; plantou a roça, mas sobraram os tocos e os da estrada para lembrá-lo de que eles ainda estão presentes. Em uma das minhas visitas à sua roça, seu Horácio contou-me, com orgulho, de quantos quilômetros os pés de fumo, que ali plantara, haviam viajado. Pety, fumo Guarani, diferente do fumo juruá, usado para a produção da neblina no petengué nos rituais da $O p y$.

A terra Guarani, segundo Meliá e Temple (2004), em sua configuração ecológica, apresenta-se com vegetação florestal, úmida, perto (até $300 \mathrm{~m}$ ) das margens de rios, lagoas ou oceanos, altitudes abaixo dos 400m do nível do mar e com temperaturas médias entre 18$22^{\circ} \mathrm{C}$. É nesse espaço que se dá a movimentação desse povo, sempre em busca de terras agriculturáveis para que as que ele deixou para trás se recuperem.

\footnotetext{
${ }^{23}$ Este seminário, realizado pelas Comunidades Guarani do Litoral e pelo CTI - Centro de Trabalho Indigenísta, em sua segunda parte, ocorreu em fevereiro desse ano, na aldeia de Jatay ty reunindo lideranças de várias partes do país para discutir a questão da terra Guarani.
}

Espaço Ameríndio, Porto Alegre, v. 2, n. 1, p. 85-110, jan./jun. 2008. 
Nesse movimento, carrega suas sementes e faz o processo de repovoamento fauno-florístico ou, como disse Marcos Tupã:

... se o Guarani ou a comunidade tá lá, ela precisa sobreviver, ou então precisa plantar algumas coisinhas, as árvores frutíferas para os pássaros chegarem e cantar... a cachoeira, o rio, os peixes (Marco Tupã, Cacique da Aldeia Krukutu, SP, entrevista em 19 fev. 2005).

A escolha da teko'á é feita no sonho, mas obedece a alguns princípios: a presença de um rio, riacho ou manancial aqüífero, a presença da palmeira pindó que, não estando ali, é plantada. A teko'á tem uma conformação tal que provocou uma descrição poética de Meliá e Temple (2004, p. 62) para exemplificar o que é sabedoria na perspectiva Guarani:

Hay que recordar que la casa de los Mbyáguaraní está casi siempre asentada al borde - "ceja" del monte o selva, frente a un campo abierto; la puerta de la casa se abre al oriente; más abajo corre un arroyo. Es así como a la mañana una tenue neblina cubre el pajonal, neblina que poco a poco se ve iluminada por los rayos de sol que se abren paso a través de ella com lenguas de luz: éstas son las llamas y la tenue neblina. Mientra tanto la selva hace escuchar la vida de la cual está llena: el croar de las ranas, los amanecidos cantos de los pájaros y al fondo el suave murmullo del arroyo.

Es la sabiduría que nace, con aquel sentimiento de alegría comparable al del investigador que descubre una nueva idea, como cuando la tenue neblina es penetrada e iluminada por el sol; es una sabiduría que sabe que está generándose como la verdad (MELIÀ e TEMPLE, 2004, p. 62).

O espaço "encolhido" proposto pelo juruá que se tornou proprietário da terra da ancestralidade Guarani vai, segundo as palavras do professor Mário, interferir na própria educação que a Escola Guarani propõe:

E então eu vejo que a educação é uma grande prioridade hoje, né, mas só para ter a sua estrutura precisa de espaços, né, porque para ter uma educação diferenciada, que muitos dizem...[aquela] que está no 
papel, teu espaço é pequeno, e aí tu não tem como avançar. Por exemplo, a Lomba do Pinheiro, que é um espaço pequeno, né, que tem uma escolinha lá, a Estiva... não adianta tu teres um pequeno espaço e uma estrutura boa, se tu não tens um espaço que dê mais condições para tu visualizar melhor o universo, então é uma coisa que... Eu achava que ali no Cantagalo, por exemplo, com duzentos e oitenta e seis hectares era o suficiente, mas no momento que eu fui me aprimorando mais a fundo [vi que] é muito pequeno, é muito pequeno, aí eu vi... no momento que a gente vê, "bá, é grande", mas no momento que a gente vai vendo mais a fundo... (MÁRIO MOREIRA, professor da Escola Estadual Indígena Karaí Arandu, 19 fev. 2004).

Aqui Mário mostra o desespero pela ausência do espaço fundamental à educação Guarani dentro desse perceber o mundo desde o mbyarekó. Como fazer para conhecer o Universo representado na mata se ela rareia? Como fazer a educação diferenciada que propõe o "papel" (o documento oficial)? Mário afirma que o Guarani faz parte

... do conjunto ambiente, ele é a floresta, ele é... somos privilegiados né, temos Nhanderú ou o ser na figura de Nhanderú que é o ser humano, daí, assim, nós indígenas, nós Guarani, nesta parte da natureza, (...) porque assim, a floresta, os animais, nós temos conhecimento assim das épocas que pode caçar, das épocas que pode pescar (MÁRIO MOREIRA, professor da Escola Estadual Indígena Karaí Arandu, 19 fev. 2004).

Se esse conhecimento não pode mais ser exercitado no dia-a-dia do viver, como ensinar a plantar, sem as grandes máquinas e os "venenos do juruâ", se a mata encolhe e a terra empobrece?

$\mathrm{Na}$ ausência da boa terra para plantar, os Guarani vêem-se impelidos a consumir o alimento industrializado, comprado nas cidades lindeiras a suas aldeias que, nem sempre, é tolerado mesmo entre os mais jovens. As falas das lideranças sempre remetem ao fato da alteração alimentar e de como "era antigamente". Dizem eles que o remédio e a comida do "branco" estão trazendo a doença para o seu povo, já que eles os retiram do modo de ser tradicional. Antigamente o 
alimento era trazido no ajaká, desde a roça; o remédio, da mata; a medicina, da prática da Opy.

$\mathrm{Na} O p y$, a primeira escola, com suas conversas, seus cantos religiosos, e na prática do ñaderekó se fazia a Educação Guarani; hoje se não há disputa com a Escola cidadã, pelo menos se complementa com ela. O professor Hugo faz uma análise disso no seu falar:

Opy é sagrado, né... porque nós sabemos que o sagrado que vão à igreja que o branco fazia, né. Tipo daquilo ali, só que a escola nossa... quase a mesma da Opy, né? Mas antigamente os Guarani fazia escola, não só dentro da Opy, era fora do Opy, assim de fora, ou seja, debaixo da árvore, ou seja, no pátio, qualquer lugar, quase tipo de escola, que educava todo dia... mas, antigamente, educando as crianças, o jovem ou para o adulto mesmo, ou para o casal como é que pode viver, então educando tipo de conselho, né? Eles falam conselho mesmo. Não são assim tipo vez em quando na escola, que nem na aula sim, antigamente era assim, mas a escola já é diferente, mas nós temos que aprender também pra falar sobre a escola, né? Porque a escola também é muito importante pra saber... é, pra saber monte de coisa assim sobre o mito, sobre leis, nossas leis, né, os Guarani que vivem além dos juruá, como é que é agora. Por exemplo, antigamente os juruá também faziam quase pouquinhas coisas dos leis para viver, ou seja, o tema do juruá aumentando também agora, né? Ensinamos [as leis], mas não muito, né? Porque a educação, a educação que antigamente fazia o karaí e o pajé e alguns líderes da aldeia, ele faz algo tipo de assim, por exemplo, ele rezava primeiramente, ele escutava o Deus dizendo pra ele. Depois de manhã ele conversava com as pessoas, juntando as pessoas e dizendo assim: "Hoje, acho que não vamos fazer nada, ou seja, hoje temos sorte pra fazer, ou seja, hoje nós vamos trabalhar juntos que o Deus pediu". Então era assim, né, antigamente era assim. Bom isso daí é educação nossa. Mas agora... agora como é que podemos, mas antigamente também, vamos falar de antigamente, que não existia nem letras, nem números, nem pra contar como é que é, então o tipo de objeto que nós vamos chamar era muito pouquinho, era menos objetos conhecemos que... e por isso que às vezes nos achamos que objetos dos brancos não podemos chamar de todos os tipos dos nossos língua, né? Não podemos chamar de todo nossa língua (HUGO 
FRANÇA, professor da Escola Estadual Indígena Guapo 'y Porã, 19 jul. 2005).

A Escola, então, vai ser necessária na medida em que os objetos que o "branco" inventou não têm nomes Guarani, porque a relação necessária à sobrevivência do povo pode ser ensinada desde a casa de reza, onde, ouvindo Deus, o karaí pode dizer se o dia é fasto ou nefasto ao fazer naquele local. Porém, há uma presença que não pode ser ignorada, que se coloca nas passagens dos potentes caminhões que trafegam ao lado da teko'á ou na estrada que possivelmente passará sobre o local sagrado da Opy ou ainda nos brinquedos e roupas tão generosamente doados pelos juruá aos Guarani.

Há uma tecnologia lá fora, uma sociedade de objetos, que não pode ser esquecida, porque não se deixa esquecer, porque intervém de forma acintosa no ser Guarani; então, há necessidade de uma Escola que diga que objetos, que nomes e que papéis eles têm na cultura que cerca e cerceia o Ñanderekó.

Quando confrontado com a possibilidade de o Estado obrigar os Guarani a freqüentarem a Escola, como faz com os juruá, e a possível resistência das lideranças, o professor Hugo mostra uma preocupação interessante:

É, é, é... e quando pensa os Guarani que pensa é assim, né? Mas eu, por exemplo, eu pensa assim, né, diferente mesmo, né, não sei se alguém concorda comigo também, que eu... o meu opinião é... assim, escola que existe aqui no Brasil, agora que vão criar o Guarani na comunidade, a escola é muito importante pra mim, né, e pra mim, por exemplo, as crianças que vão nascendo agora, que vão crescendo e sem saber nada, sem falar português, ou seja, sem conhecer nada, pelos caminhos, mais pra frente, será que ele viverá assim também? Então tudo isso eu tô pensando eu, né? Eu, por exemplo, já tenho mais de vinte anos, então eu nem... se eu ficasse sem ler, sem escrever, ou seja, sem conhecer escola, será que eu poderia trabalhar também assim fora, ou seja, será que eu poderia viajar longe daqui, como é que posso fazer tudo isso como o branco? Então tudo isso que está acontecendo agora. Ainda melhor a escola, né? Ainda bem que aconteceu nossa escola pra aprender um pouquinho mais dessas coisas (HUGO FRANÇA, 
professor da Escola Estadual Indígena Guapo'y Porã, 19 jul. 2005).

Diferente do seu Horácio que teme que o saber ler e escrever coloque os Guarani no limbo da intersecção cidadã, Hugo teme o que ocorrerá com as crianças que não conhecem esta intersecção; como poderão se movimentar neste meio atraente e inóspito do juruarekó, ou seja, será que "pelos caminhos, mais pra frente, será que ele viverá assim também?" E se, seduzido pelo canto da sereia do trabalho e do salário, ele resolver "ser alguém" na cidade? E se o ambiente necessário ao ñanderekó não existir mais? E se...

O precavido professor Hugo pensa no futuro como pensam também os professores face à proximidade da tecnologia revelada nas falas do Mário, quando perguntado sobre como fazer educação ambiental na teko'a:

A parte guarani, eu vejo que deve ser trabalhado, né, com um bom diagnóstico assim, mais assim, local, é conversando que tu vai mostrando... e ali as crianças vão se sensibilizando da sua situação local. Depois dali fora da aldeia eles vê. Ai a gente tem dois projetos ali, que é trabalhar com a captação de animais que têm ali. Eles mesmos desenham como é que eles vêem aquele tipo de animal, a sua cor, porque ali falta muito animal, a gente tá trabalhando com isso, né, para eles... ai eles também vão tendo aquela criativa em desenhos, em pinturas, no momento ali tu vai dizendo a importância, hoje um pouco da sua preservação, um pouco de que tu tens que consumir, então passando vídeo que é uma das grandes formas de explicar que a gente tem, porque eles gostam ver animais, porque, por exemplo, o canal dois que é a Guaíba, né, fazem direto, passa sobre isso, sobre ambiente (MÁRIO MOREIRA, professor da Escola Estadual Indígena Karaí Arandu, 19 fev. 2004).

E na fala de Marcos Tupã (Cacique da Aldeia Krukutu, SP, entrevista em 19 fev. 2005) sobre a incidência da mídia dentro da aldeia:

... eu sou um que defendo que ... eu acho que a estrutura básica, é importante ter energia, posto de saúde, escola, computador, porque computador é instrumento de trabalho ... e aí outras aldeias que têm 
televisão, têm muita influência, imagem de propaganda, consumismo, acaba sendo influenciado. Na minha aldeia, todas as casas têm televisão, têm fogão e devido a uma situação também que não tendo uma atividade para fazer, cortando lenha ... (Marcos Tupã, Cacique da Aldeia Krukutu, SP, entrevista em 19 fev. 2005).

A tecnologia não pode mais ser esquecida. Ela é instrumento de trabalho, "o computador é instrumento de trabalho", ou então "o vídeo, que é uma das grandes formas de explicar que a gente tem, até porque a televisão e o vídeo também são lazer".

O desejo da técnica como contraponto do mero estar é uma realidade presente. Traduzo esta afirmação na fala de Marcos Tupã (Cacique da Aldeia Krukutu, SP, entrevista em 19 fev. 2005):

... eu tenho televisão. Para dizer a verdade, eu tenho duas televisões em casa, uma no meu quarto e uma para as crianças. Só que eles acabam ficando mais fora de casa do que ficar preso, até porque a linguagem, as informações... eu dou graças a Deus [que eles não entendem]. Então eu vejo assim que, quando começa as aulas, as crianças maiorzinhas vão para a escola estadual, ficam até ao meio dia presos, né, bem dizer presos, né? Aí quando saem, eles querem correr, brincar, tem represa para nadar ... (Marcos Tupã, Cacique da Aldeia Krukutu, SP, entrevista em 19 fev. 2005).

A televisão já está a postos, mas a observação e as respostas ao questionamento apontam para o fato de as crianças não se deixarem seduzir pelas imagens mais do que se seduzem pelo rio, pela mata ou pelo próprio terreiro onde fazem suas brincadeiras.

O aproximar-se, talvez curioso, talvez zeloso de sua própria

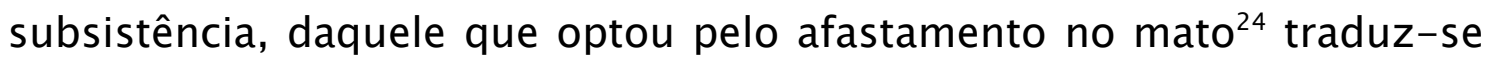
no maravilhamento da técnica obtida na proteção cidadã. O "ser alguém" nesse local também às vezes seduz. Porém, "ser alguém" na cidade é a negação de sua própria essência de indígena Guarani e M’byá. Fica o impasse entre o "mero estar" e o "ser alguém". Resta a Escola como uma

\footnotetext{
${ }^{24}$ Segundo Garlet (1997), os Kayguá ou os "do mato", à medida que a colonização avançava sobre as suas terras, embrenhavam-se no mato em fuga dos encomendieros e da proposta de civilização ocidental, tornaram-se hoje os antepassados dos M'byá.
}

Espaço Ameríndio, Porto Alegre, v. 2, n. 1, p. 85-110, jan./jun. 2008. 
saída e um esclarecimento da técnica que possibilita ao juruá "ser alguém". Algumas lideranças já se posicionam contra a escola, pois se esta serve bem ao "branco", servirá ao Guarani? Outras pensam que esta mesma escola é o espaço de resistência ao avanço da sedução do objeto, mas, para isso, não negam o uso do próprio objeto; outras, ainda, vêem-na como um viés que garantirá outra forma de sobrevivência ao seu próprio povo se o ñanderekó se perder, ao perder o local onde ele pode acontecer.

Há, contudo, uma apropriação de fato na forma de ser da própria escola nas comunidades. Embora o imaginário escolar coloque classes uma atrás da outra frente a um quadro de giz, e o professor escreva os temas de discussão, o enfoque desses temas foge daquilo que as escolas tradicionais juruá trabalham. Escritos em Guarani, eles falam das coisas deles próprios, criam seus próprios códigos para traduzir o concreto, e o estar ambiental situa-se no âmbito mitológico-religioso em que perceber é mais que conhecer.

Se os Guarani mantêm os seus mitos para explicarem o como e o porquê de aqui estarem, nós, os juruá, abandonamos os nossos, mas criamos outros que podem estar encarnados no próprio pensamento científico, naquele que alavanca a técnica e amplia os poderes de quem dela se apropria e, se os Guarani criticam o juruárekó que modifica o ambiente, usando-o para produzirem seus objetos e ampliarem sua própria técnica, por outro lado não vêem mais escapatória, pois, como não há mais o mato para onde fugirem, então há que, nesse momento, compreenderem essa própria técnica que pode estar representada na Escola.

\section{Referências bibliográficas}

DORNELES, Malvina do Amaral et al. (Org.). Ayvu Anhentenguá. Porto Alegre: UFRGS/SEC, 2005.

GARLET, Ivori José. Mobilidade mbyá: história e significação. 1997, 322f. Dissertação (Mestrado em História Ibero-americana) - Instituto de Filosofia e Ciências Humanas, PUC-RS, [1997]. 
HEIDEGGER, Martín. La pregunta por la cosa. Buenos Aires: Editorial Sur, 1964.

Ser e tempo. Petrópolis: Vozes, 2002.

KUSCH, Rodolfo. La Seducción de la barbarie: análisis herético de un continente mestizo. Buenos Aires: Editorial Raigal, 1953.

Geocultura del hombre americano. Buenos Aires: Fernando Garcia Cambeiro, 1976.

. América profunda. Buenos Aires: Editorial Bonum, 1986.

LADEIRA, Maria Inês; MATTA, Priscila. Terras Guarani no litoral: as matas que foram reveladas aos nossos antigos avós $=$ Ka'agüy oreramói kuéry ojou rive vaekue y̆. As matas que foram reveladas aos nossos antigos avós. São Paulo: Centro de Trabalho Indigenista, 2004.

MELIÀ, Bartolomeu; TEMPLE, Dominique. El don, la venganza y otras formas de economía guaraní. Asunción del Paraguay: Centro de Estudios Paraguayos "Antonio Guasch", 2004.

PINKER, Steven. Tábula rasa: a negação contemporânea da natureza humana. São Paulo: Companhia das Letras, 2004. 


\section{Anexo 1:}

\section{Tabela descritiva dos símbolos empregados pelo professor Hugo nas aulas de} Matemática

\begin{tabular}{|c|c|c|c|}
\hline \multicolumn{2}{|c|}{$\begin{array}{l}\text { Número usado na } \\
\text { Tekoá }\end{array}$} & Indo-arábico & Explicação \\
\hline$\sim$ & & $0-$ Zero & $\begin{array}{l}\text { É um túnel da minhoca, pois onde ela passa não fica } \\
\text { nada. }\end{array}$ \\
\hline$\uparrow$ & Peteĩ & $1-\mathrm{Um}$ & $\begin{array}{l}\text { Uma só flecha era que os guarani precisavam para vencer } \\
\text { o oponente devido a sua valentia. }\end{array}$ \\
\hline$\uparrow$ & Mokoĩ & $2-$ Dois & Uma flecha quebrada representa duas coisas. \\
\hline 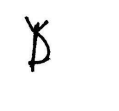 & Mboapy & 3 - Três & $\begin{array}{l}\text { São três os objetos que formam o arco: a corda, a madeira } \\
\text { e a cordinha. }\end{array}$ \\
\hline Y & Irundy & 4 - Quatro & É um sapo pulando, onde se observa suas quatro patas. \\
\hline$\downarrow$ & Ja’o & 5 - Cinco & É a flecha usada pelos índios bravos - a lança. \\
\hline DO & Ja'ove & $6-$ Seis & Dois arcos, ou duas vezes 3 . \\
\hline$\leftrightarrow$ & Ja'oave & $7-$ Sete & Arco e flecha. \\
\hline$\varphi$ & py ${ }^{\text {Ja'mboa }}$ & 8 - Oito & $\begin{array}{l}\text { Anhamba'i mirin - planta de folha com oito folíolos, que } \\
\text { nasce no Paraguai, Argentina e Brasil e que se usa como } \\
\text { remédio. }\end{array}$ \\
\hline 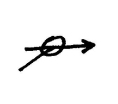 & Jarundy & 9 - Nove & $\begin{array}{l}\text { Acrescenta-se uma flecha a folha de oito folíolos, temos } 9 \\
\text { objetos. }\end{array}$ \\
\hline
\end{tabular}

Espaço Ameríndio, Porto Alegre, v. 2, n. 1, p. 85-110, jan./jun. 2008. 


\section{Anexo 2:}

\section{Glossário $^{25}$ de termos Guarani empregados no texto}

Ajaká: cesto.

Avaxi: milho.

Avaxi mitã: milho pequeno ou milho criança.

Boja'o: três flechas partindo do mesmo ponto, que nas representações do professor Hugo, indica a divisão.

Cunhã: mulher. A grafia kunhã é bem utilizada.

Guapo'y Porã: segundo a tradução do Professor Hugo, significa Figueira Bonita, porém a tradução grafada na publicação "Terras Guarani no Litoral" (LADEIRA E MATTA, 2004, p .23) traz o significado de Campo Bonito.

Guaxu: veado (Ozotoceros bezoarticus e Mazama americana).

Irundy peteĩ ve: o algarismo cinco, representado por quatro mais um.

Irundymboapy: o algarismo sete, representado por quatro mais três.

$J a^{\prime} o$ : metade de algo.

Jata 'ity: butiazeiro (Butia capitata)

Juruá: referência aos humanos que não estão na cultura guarani. Juruá, neste caso, são todos os que não falam a língua ou não têm a cultura Guarani, independente de sua etnia. Desta forma, são juruá os brancos, negros e índios que não estão na cultura Guarani.

Juruá rekó: modo de viver dos juruá ou dos não-índios.

Ka'yguá: selvagens, homens do mato, denominação das parcialidades Guarani que não se submeteram às reduções jesuíticas e refugiaram-se nas matas. Há fortes indícios que os Mbyá são descendentes destes grupos.

\footnotetext{
${ }^{25} \mathrm{O}$ glossário foi construído a partir das leituras e das conversas com as pessoas-guarani. Há, contudo, que enfatizar as mais diversas formas de escrita e tradução são encontradas para algumas palavras, tais como avaty/milho, tal como Garlet (1997) grafa, e a correção feita por Vera Pothy da grafia, como avaxi. Por outro lado, há a grafia estabelecida pela gramática espanhola e a grafia baseada na gramática portuguesa, problema este que causou dor de cabeça ao meu tradutor - Vera Pothy - em relação aos textos do professor Hugo França, já que este foi alfabetizado em espanhol.
}

Espaço Ameríndio, Porto Alegre, v. 2, n. 1, p. 85-110, jan./jun. 2008. 
Karaí (homem) kunhã karai (mulher): normalmente representado pelos idosos, são os chefes religiosos que presidem os rituais.

Karaí Xondaro: são os karaí que foram guerreiros em sua juventude. Possivelmente xondaro seja uma corruptela do termo soldado.

Kechuita: figura mítica, talvez uma corruptela do termo jesuíta.

Koxí: porco do mato (Tayassu tajacu).

Kue: uma flecha de duas pontas que nas representações do professor Hugo indicava a operação de divisão.

Kuyri'ngue: criança. Esta grafia me foi indicada pela professora Silvana de Jata'ity. Pode ser grafado também Kyrĩgue ou Kyringue.

Mboapyapy: o algarismo seis, representado por três mais três.

Mundéo: armadilha com a qual faz-se a caça do tatu (Dasypus hybridus).

Ñanderekó: Nosso modo de ser. O modo de ser Guarani, sua cultura, também denominada Guaranireko ou Mbyáreko, referindo-se a esta parcialidade.

Nanderu Pápá Tenondé: O Pai de tudo que existe, e o Pai de si próprio. Deus primordial, que primeiro criou as palavras. É ele que pensa e transforma o mundo.

Ogueji: uma flexa apontada diagonalmente para baixo, que nas representações do professor Hugo, indicava a operação de subtração.

Ojeupi: uma flecha apontada para baixo, que nas representações do professor Hugo, indicava a operação de adição.

Opy: Casa de reza. Lugar sagrado onde se está junto.

Petengué: cachimbo usado nos rituais da Opy ou no dia-a-dia nas conversas em volta da fogueira.

Pety: tabaco (Nicotiana tabacum) que é queimado no petengué.

Pindó: palmeira mítica (Wodyetia bifurcata).

Porã: bonito, formoso.

Pynó: vegetal do qual se retiravam as fibras para a fabricação de roupa. Segundo Verá Pothy é uma urtiga gigante e, por não me ter sido apresentado, não consegui estabelecer sua espécie.

Tambeó: tanga usada pelos antigos Guarani.

Espaço Ameríndio, Porto Alegre, v. 2, n. 1, p. 85-110, jan./jun. 2008. 
ROSEMARY MODERNEL MADEIRA - Reflexões sobre a escola Mbyá Guarani ...

Tekó: o modo de ser, o modo de viver, a tradição que se revela no ser do Guarani. Teko'a: lugar espacial que contém o tekó. Outra grafia utilizada é Tekoá.

Tupyjaá: saias usadas pelas mulheres Guarani, feitas de fibra de palmeira. Xi'ý: quati (Nasua nasua).

Espaço Ameríndio, Porto Alegre, v. 2, n. 1, p. 85-110, jan./jun. 2008. 